\title{
FACTORS INFLUENCING High SCORES IN THE FOOD AND NUTRITION Practical Examinations in ESWATINI
}

\author{
Molyn Mpofu ${ }^{1)}$, Carol Phindile Dlamini' ${ }^{2)}$ \\ ${ }^{1)}$ University of Eswatini, Swaziland \\ E-mail:molynmpofu@gamil.com \\ ${ }^{2)}$ University of Eswatini, Swaziland \\ E-mail: dlaminicp8@gmail.com
}

\begin{abstract}
The Eswatini Food and Nutrition (FN) examination results have shown that the practical examinations had higher scores than the theory papers, creating negatively skewed distributions. Students were scoring high marks in the FN practical examination component than in theory. This study sought to explore the factors that influence the allocation of high scores in FN practical examinations in Eswatini. A descriptive research design utilizing the qualitative research approach was employed. A sample of 17 participants was purposively selected, comprising of $10 \mathrm{FN}$ teachers, 3 subject Regional Inspectors, 3 Moderators and one Subject Officer. Focus group discussions, interviews and document analysis were used to collect data. Thematic analysis was the tool used to analyse qualitative data obtained from interviews and focus group discussions. The study established that teacher competency levels were low as evidenced by unclear marking schemes. Schools lacked resources, which compromised on the monitoring and supervision of examinations. The study also established that FN practical examination assessment was subjective and that the use of a well-defined marking scheme could minimize the variations. Since FN is a practical subject, students needed to practice cookery tasks during the course of the year, hence students were more likely to excel during the end of year practical examinations. The study recommends discussion of assessment tools and continuous training for examiners before marking of the practical examinations.
\end{abstract}

Keywords: Dynamics; Elevation; Food and Nutrition; Practical Examinations

\section{INTRODUCTION}

Food and Nutrition (FN) is the most significant domain or specialty of the Consumer Science curriculum (Swaziland General Certificate of Secondary Education (SGCSE) Food and Nutrition Syllabus, 2017-2018). Research has shown that assessment of Consumer Science practical examinations is laden with a number of inconsistencies in examination practices and procedures. A study conducted by McSweeney (2014), in Ireland indicates that curriculum and assessment arrangements at senior cycle were inappropriate and negatively affected quality of learning. Some teachers showed unethical behaviour around the completion of journal tasks. McSweeney (2014) felt it was not safe to view national assessment results as a valid indicator of learning and achievement standards in the subject, teachers can have a narrow view of assessment and often unsure about how to respond to evidence from students' actions, projects and processes. On the same note, Leepile (2009) in his study on
Assessment and Quality Assurance of Home Economics coursework in senior secondary schools revealed that teachers and moderators interpret mark schemes differently, resulting in inconsistencies in the assessment of Food and Nutrition practical examinations.

Assessment is a major aspect in education and an essential component of teaching and learning. The effectiveness of evaluation and assessment relies largely on ensuring that both those who design and undertake evaluation activities possess the proper skills and competencies (Organization for Economic Co-operation and Education (OECD), 2013). Possession of adequate skills and competency is crucial to provide the necessary legitimacy to those responsible for evaluation and assessment (McSweeney, 2014). Students work can be assessed internally, externally or sometimes by a combination of the two (Leepile, 2009).

In order for an assessor to tell if students have done well or bad in an examination or test, it is essential to analyse the variability of scores within the group and to interpret the 
distribution of the scores. Answers to the following questions can be very helpful: Did all the students get similar scores? Did some students perform better than others in the same class? This implies that all students had the same amount of knowledge or the scores varied widely from each other (Heald, 2018). When scores are normally distributed, a normal distribution bell curve is symmetrical. This implies that half of the data will fall to the left of the mean and the other half on the right (Holroyd, 2015). In this case fewer scores are at the end on both sides representing the high and low scores (Brown, 2017). Such a curve shows that the test was neither too difficult nor too easy. A skewed distribution would mean that scores are clustered together right around the top or on the other end. This could mean all students demonstrated a mastery of the material or the test was easy or most of the students failed because either the test was difficult or the teacher failed to properly explain the content (Heald, 2018). When scores are mostly low, a curve is said to be positively skewed because the majority of the scores fall in the lower part of the distribution with few high scores (Andrew \& Carol, 2014). If the curve is negatively skewed, the majority of the scores fall in the upper part of the distribution with many high scores and few low scores causing a tail on the left (Brown, 2017).

According to OECD (2016), many countries of the continent submit a continued debate that teacher based assessments are perceived unreliable due to possible cheating with a high risk of bias between groups of students. Variations in grading standards between the teachers themselves and schools often render internal assessment results to lack external confidence for comparison between schools. Nair et al., (2014) noted in their study that teachers encountered problems with completing the assessment on time and ensuring the authenticity of assessment. Heynes (2014) argued that, in external assessment, the awarding body is in direct control of the mark or grade awarded to each candidate through the individuals it appoints to make the assessment decisions and has less control over school-based assessment. School Based Assessment (SBA) is more challenging and places more responsibilities on teachers, as they have to play a dual role of teacher and assessor (Cheung \& Yip 2015). It is generally builds a broader accountability of achievement and create less pressure on teachers. Conversely, there are arguments against the use of school-based type of assessment.

Eswatini Education System at senior secondary level has adopted an international trend whereby school-based assessment is a combination of both internal and external assessment. Since the inception of FN in 1990 in Eswatini high schools, FN practical examinations involved the use of six external assessors who were Regional Consumer Science Inspectors. According to Manana (2016) the external examiner based approach in the assessment of FN practical examinations was associated with a number of challenges, including high travelling cost of external examiners, power failures, and impossible roads on rainy days and timetable interruptions resulting to inevitable waste of resources and disturbance to candidates as schools postponed the practical examinations. Thus, the Examination Council of Eswatini
(ECESWA) introduced SBA in the assessment of FN practical in 2015 seeking to attain a relief from the strain (Manana, 2016). To prepare for the change in assessment, national workshops were conducted in 2014 by ECESWA where teachers were trained on the new approach of assessment. This was done through allowing coordination sessions during training and enabling teachers to mark dummy practical planning sheets using the new assessment tool (banded mark scheme).

The Eswatini FN examination results have over the years shown that, the practical examinations had higher scores than the theory paper, creating negatively skewed distributions. Students were scoring high marks in the FN practical examination than in the theory paper (Manana, 2016). The ECESWA Consumer Science subject officer in a seminar at the University of Eswatini in 2018 on Measurement and Testing in Consumer Sciences mentioned that there were inaccuracies in $\mathrm{FN}$ practical examination assessment as teachers were awarding students very high marks as a result their graphs were always negatively skewed (see Table I). Hence, the study sought to explore the factors that influence the allocation of high scores in Food and Nutrition practical examinations.

TABLE I

THE SUMMARY OF MEAN SCORES FOR FN THEORY AND PRACTICAL SCORES FROM 2013-2017

\begin{tabular}{lcllll}
\hline Paper & $\mathbf{2 0 1 3}$ & $\mathbf{2 0 1 4}$ & $\mathbf{2 0 1 5}$ & $\mathbf{2 0 1 6}$ & $\mathbf{2 0 1 7}$ \\
\hline Paper 1 (Theory) & 45.5 & 44.7 & 50.5 & 44.7 & 48.5 \\
Paper 2 (Practical) & 65.8 & 64.0 & 74.0 & 72.7 & 73.8 \\
\hline \multicolumn{2}{l}{ Source: Cambridge Report (2017) } \\
\multicolumn{1}{l}{}
\end{tabular}

\section{Methodology}

\section{A. Research Design}

The study employed the qualitative approach using the descriptive research design. The researchers employed triangulation in data collection procedures in order to increase the trustworthiness of the data.

\section{B. Population}

The target population of the study was two hundred and eighty seven (287) Consumer Science specialists to include FN teachers in Eswatini high schools, Regional Subject Inspectors, FN practical examination moderators and the ECESWA Consumer Science subject officer.

\section{Sample and Sampling Procedures}

Purposive sampling was used to select seven (17) participants: ten (10) FN teachers, three (3) regional subject inspectors, three (3) FN practical moderators and one (1) ECESWA subject officer. These participants were considered because of their expertise and experience in the assessment of FN practical examinations. The FN teachers were the main stakeholders of the subject involved in the assessment of the FN practical examinations. 


\section{Instrumentation}

Face-to-face interviews, FGDs and document analysis were the instruments used to collect data in this study. Semistructured interviews were developed for regional inspectors, FN practical examination moderators and ECESWA subject officer, and a FGDs guide was developed for FN teachers. The questions were oriented around $\mathrm{FN}$ practical examination assessment.

\section{E. Trustworthiness}

Trustworthiness of the study refers to the extent to which the data and data analysis are believable and can be trusted. Trustworthiness includes credibility, transferability, dependability and conformability (Creswell, 2014). To ensure Credibility, data collection methods were triangulated, faceto-face interviews, FGD and document analysis were used to collect data. The researchers audiotaped all the individual interviews including the FGDs for the research, typed all the transcripts of raw data, and kept the tapes and notes. For transferability in this study the population, sample, procedures, research findings and conclusions have been described in detail. Dependability in the study was addressed by providing full details of the research design and data generation through document analysis. While confirmability in the study was achieved by the triangulation of data collection procedures and data sources.

\section{F. Data Collection and Analysis}

On scheduled dates, the researchers travelled to the participants' places of work to conduct the interviews. FGDs were held at William Pitcher College in Manzini, as it was a central place for participants to meet with ease. Both interviews and FGDs were tape-recorded and notes taken and transcribed. Thematic content analysis was used for the qualitative data from interviews and focus group discussions. The data were coded and sorted according to themes, which were integrated and summarized in form of tables.

\section{RESULTS AND DISCUSSION}

\section{A. Results}

Through interviews and focus group discussions the teachers, moderators, regional inspectors and the Consumer Science subject officer were asked to state the factors that contributed to the awarding of high scores in FN practical examination assessments.

The interviews and focus group discussion findings reflected that there were various factors that influenced awarding of high scores in Food and Nutrition practical examination assessments. There were five themes established in the study as the common factors that influenced the allocation of high scores in Food and Nutrition practical examinations at high school level in Eswatini, which included teacher factors, school factors, student factors, assessment procedures and assessment tools. The themes were further elaborated in sub-themes as indicated in Table II.
TABLE II

THEMES AND SUB-THEMES FROM THE STUDY

\begin{tabular}{ll}
\hline Themes & Sub-Themes \\
\hline Teacher Factors & Competency level for teachers-some \\
teachers are inexperienced & Teacher's attitude \\
Teacher's failure to do their part \\
Teachers performance judged by their \\
students' performance \\
Lack of faithfulness of teachers \\
Lack of motivation and commitment \\
Teachers' failure to capture all \\
process during students working
\end{tabular}

$\begin{array}{ll}\text { School Factors } & \begin{array}{l}\text { School resources } \\ \text { Head teacher's failure to provide } \\ \text { invigilators }\end{array} \\ \text { Student Factors } & \text { Students characteristics } \\ \text { Assessment Tools } & \text { No marking guide-assessment tool } \\ & \text { not clear and unpacked } \\ & \text { Test items too open } \\ & \text { Set standards are subjective } \\ & \text { Lack of exams supervision and } \\ \text { monitoring } & \text { Lack of training for the teachers } \\ \text { Assessment Procedures } & \text { Moderation of students' scores } \\ & \text { Weighting adjustment }\end{array}$

\section{1) Teacher Factors}

a) Competency Levels of Teachers

Findings revealed that teacher competences in the practical assessment was very crucial as some teachers were inexperienced, they failed to interpret the test questions and marking schemes. The researchers also observed that teachers lacked the knowhow of assessing and awarding of marks. Thus, they awarded the high scores because they did not know and they see nothing wrong. This was also echoed by Participant 5 that:

"You find that may be the teacher did not understand the test question as there is no marking guide to follow for each test question, not knowing how to approach the test question"

Participant 2 shared the same sentiments that:

"Teachers still do not understand the assessment itself, if you do not understand something; you do not award the appropriate scores. Teachers do not understand the marking of the choice of work, method of working and quality of dishes thus are lenient when marking. Students not well taught the method of working because teachers themselves do not understand it. They tend to award high scores, as they see nothing wrong with the order of work because they do not know "(Participant 2).

According to Participant 2, teachers' level of understanding influence awarding of scores. The findings indicate that teachers lack understanding of what is assessed; how to assess and award marks, as a result, they give students inflated scores. 


\section{b) Teachers' Failure to do their Part}

The findings revealed that when teachers discover that their students are lacking in certain skills due to their failure to finish the syllabus, they fail to assess objectively. This view may suggest why teachers tend to be lenient when assessing. Even if a student has produced a piece of work that does not meet the set requirements, teachers may still award high marks as they feel they cannot fail the students for something they did not teach. Some teachers feel guilty that the learners did not do any practical sessions during the term, so to penalize a child for something they did not do is not right.

"How do you expect me to penalise students on things that I have not taught them, I cannot expose myself thus, marks awarded will be high. As the teacher is assessing the students, is assessing him/herself as well, the results will be reflecting his/her work" (FGD).

\section{c) Teachers Judged by their Students' Performance}

Most of the participants revealed that teachers' performance is always measured by students' performance hence teachers award high marks. Teachers know that when students' performance reflect on them.

"Teachers performance is always measured by students" performance. You cannot afford to give low marks yet in the end it will reflect back to you. As you assess the students, you are assessing yourself as well. The results will not only reflect the teacher's performance but the schools' as well". (FGDs)

Participant 4 submitted that:

"As long as teachers are assessed by their own students' performance they will keep inflating the results".

In addition, Participant 7 shared the same sentiments that:

"Students performance reflect badly on the teacher, marking tend to be non- objective".

These findings indicate that teachers deliberately inflated students' scores.

\section{d) Lack Motivation and Commitment}

The findings revealed that teachers were careless, lacked motivation and were not commitment to assess as such they did things anyhow. Teachers felt burdened by the workload that comes with SBA but could be motivated if given incentives. At the same time ECESWA was doing very little to ensure teachers are prepared for the practical assessment task. One participant said that with frustration:

"SBA is demanding to teachers. Teachers need to get incentives for marking to be motivated and do their work hard. There is too much work involved in sheet 1, 2, 3 while marking the practical and writing of comments" (Participant 6).

Participant 7 expressed that: "teachers awarded scores any how because they were not motivated. Lack of motivation because if they do not understand they would ask for help."

This shows that if teachers were motivated they could be committed and mark diligently even though SBA was demanding. With motivation and commitment even if one does not understand, would ask for help. e) Teachers' Failure to Capture all Processes during Students Working

The practical assessors need to be observant and vigilant in order to be able to capture all the steps when students are working during the practical. One of the Participants indicated that some students make mistakes during the working, but because the numbers were big, it was not possible for the teacher to follow all the processes for each of the eight students at once. Teachers up concentrating at the final product as a result, students end up getting a total in skill manipulation.

"They fail to operationalise from step to step in order to get 50 marks, what is it that you should have done...at mark 5 and 10 what did you do. Because there are 8 students one teacher cannot observe all of them at once, thus teachers end up estimating/ fabricating the marks in this section" (Participant 7).

Results also revealed that because of the large groups with little time for assessing teachers end up leaving late and their vigilance during marking as the day progresses was affected, they get tired.

"If you have so many students it is tiresome, having to prepare the lab after each group is hectic. When the teachers are tired, they don't move around doing the work/assessing. They end up awarding marks without proper following the right channel (FDG).

The findings indicate that because of the pressure that comes with the practical exams teachers end up failing to capture the students' working methods and skill manipulation as a result teachers end up giving students inflated marks in this section.

\section{2) School-Related Factors}

\section{a) Availability of School Resources}

The participants revealed that students' exposure to equipment use enabled them to operate them with ease and come up with interesting dishes that help them to achieve higher scores.

"Times have changed, as we are developed most homes own different kinds of equipment- electric stoves, blenders, electric mixers etc., that enable students to operate them with ease and they even practice at home. As the days go by the students are more exposed thus are more likely to score higher in the practical. Besides if you are exposed to these things you are going to perform better" (FGD).

However, it was also noted during the discussion that in some schools students were limited by equipment, so teachers find themselves in an awkward position as they cannot penalize their students since it was not the candidates' fault that the equipment was not there.

"Every time I conduct practicals I have to teach my students how to operate an electric stove, even during the exam "since they don't have them at home. For example, If a student is to use a blender as per a test question, there is none in the school and as a teacher you also don't have, you cannot penalize the student. You will 
be lenient because it's neither the student's fault nor the teacher's" (FGD)

Some participants felt that students' exposure to equipment and dishes contribute significantly to their performance in FN practical examinations. In some schools students are well prepared, practicals afforded and equipment is available thus scores were more likely to be good. One participant submitted that:

"Students not do practicals because of the lack of school funds thus, teachers give away marks" (Participant 3).

Another participant argued that:

"Some teachers attend workshops and others don't whereas it's where teachers get training or it could be that teachers are not interested or administrators not giving money to attend workshops" (Participant 4).

These findings indicate that availability of resources in a school expose students to a number of things and thus acquire many practical skills. Students from schools where practicals are done more frequently and appropriate equipment used are more likely to come up with interesting dishes and score higher in practical examination.

\section{b) Head Teachers' Failure to Provide Invigilators}

It emerged that in some schools there was no invigilation of the practical exams including planning as a result teachers were tempted to offer some help to their students. The students have the opportunity to ask from the teacher. As it was motioned earlier that students performance is used to evaluate teachers performance, the teacher will be tempted to tell the students. One participant remarked that:

Head teachers do not provide invigilators for us during the planning time, as a teacher you find yourself asking the student.....hey what is this and the students have the opportunity to seek help from the teacher. I try to convince the deputies to provide the invigilators but none, I even run away if it's not my group because I know my colleague will help her students and she does the same with mine (FGD).

"The school based assessment is the cause of all this" (Participant 7), "it has taken away the value of the subject” (FGD).

The findings revealed that teachers could find themselves tempted to help and guide the students during the planning and practical sessions if school administrators fail to provide invigilators.

\section{3) Student Factors}

Findings revealed that teachers' knowledge of students influence their judgement. As teachers know the characters and weaknesses of each student, they find themselves being lenient. For example, student not doing well in theory yet he/she is good, respectful and very responsible. It was also noted that some students are very good with practicals and most students tend to do well because FN was a practical subject.

"There are students who are good, respectful and very responsible but they eye..... At the same time you know the student has good cooking skills yet very poor in theory". You would find out that it would be difficult for a student to get 30 or $40 \%$ in theory " (FGD).

Participant 1 alluded to the fact that teachers' preference over students can influence his/her judgement when she said:

"The only difference with us (external assessors) is that I did not go to the exam having in mind that student so and so will excel. I went there knowing that every student had the ability to perform well with any favouritism. There are these teachers who would want to influence you in a way by telling you that there is student so and so who is good" (Participant 1).

These findings reveal that teachers' preference of certain students over others and previous performance influenced their marking.

\section{4) Assessment Tools}

\section{a) Unclear Banded Marking Scheme}

The findings revealed that the banded mark scheme was not specific thus not reliable, as a result it was subjective, not objective. For example, given to different teachers to mark the same things they could come up with different scores. This shows that the teachers interpret the marking tool differently and their understanding varies. There are no specifications for each test question as a result scores awarded depends on that particular teacher's understanding or interpretation.

"The tool is not specific; we end up awarding more marks because the tool is not specific and unreliable. If you give teacher $A$ and teacher $B$ to mark the same work they will not come with the same mark" (FGD).

Another participant shared the same sentiments:

'Assessment tool is too broad. It's not that teachers don't know but about the difficulty of marking the practicals only if there could be a breakdown of marks, which are itemised to guide stating what need to be done e.g. using a vegetable knife for chopping vegetables, if a butcher's knife is used you subtract a mark because a wrong tool is used. The assessment tool is not unpacked, for instance in DT and for the first time their marks were accurate" (Participant 7).

The participants also mentioned that the assessment tool could pose a challenge, if teachers were not sure about it. Teachers' failure to implement the banded mark scheme is the cause of teacher's failure to award scores appropriately. The findings have revealed that because of the subjectivity of the marking tool examiners tend to award high marks.

\section{b) Test Questions Too Open}

Exam test questions sometimes are too broad such that it becomes difficult for both the learner and the examiner to deduce what is required, hence confusion is created. For example, Participant 6 mentioned that in 2018 a question required students to prepare three dishes using ingredients found in the cupboard. There are a number of ingredients, even those that can be used in very small amounts like salt, stock cubes etc. Test items should always be clear and straight to the point so that both students and teachers understand it. Another participant added that: 
"You find that even the teacher did not understand the questions being too theory oriented e.g. students asked to prepare a dish to illustrate emulsification" (Participant 5). These findings indicate that it was challenging to mark subjective tests and it is the cause of unreliable marking.

5) Assessment Procedures

\section{a) Lack of Supervision and Monitoring of Assessors}

The study revealed that because of ECESWA reliance on schools and teachers for the assessment of FN practical examinations some schools did not supervise teachers nor provide invigilators as a result teachers did as they pleased. Participant 7 submitted that heads of departments in schools do not bother to help even the new teachers joining the field.

Another factor is lack of supervision from the heads of departments in schools don't supervise, they just don't care.....teachers do as they please as a result. Reliance of ECESWA $s$ on teachers....teachers know ECESWA is relying on them for assessment, they are able to do things without ECESWA seeing..... in fact ECESWA is not there to see what they are doing (Participant 7).

Participant 7 said with frustration:

"Even if the invigilators are there, they don't have the expertise.....they are there to observe the working, they don't have the function to see if one has marked well....they only see the teacher busy without exactly knowing what is being assessed. Their function is not effective, as they do not have the right to assess what is going on. There is no witness for what the teacher is writing. The exam board does not have video evidence. ECESWA rely on the teachers because there is no live video and teachers know that".

The findings indicate that some teachers do things anyhow because they knew that nobody sees what they did. Some teachers do not adhere to the assessment guidelines from ECESWA. Head of departments in schools do not orient new teachers; no one cares what they do and how they do it. It is essential that the examining body ensures that all teachers and every school involved follow and adhere to set assessment guidelines and procedures so that the practical examinations scores are trustworthy.

\section{b) Lack of Training}

The findings indicated that lack of teachers' in-service caused variations in the interpretation of test questions and assessment tools hence the awarding of high scores. Training was done during the inception of SBA thus there are gaps as more teachers joined the field. Teachers were not prepared before they start marking to ensure they understand how to implement the banded mark scheme and the test questions.

"Teachers should be called every year before marking starts to remind them of what is expected and how are they supposed to do to avoid variations when the tool is used. Remind teachers about the quality of dishes, low skilled dishes like custard sauce, baked egg custard may be probably okay in JC but not at senior level" (Participant 6).
These findings revealed that lack of teachers training on assessment contribute to the inflated marks allocated to students. Training is essential to ensure that teachers have the same level of understanding and uniformity in their assessment. This may also benefit the new teachers. This shows that it was of utmost importance to train teachers/ assessors before they begin marking the practical examinations.

\section{c) Moderation of Students' Scores}

The findings revealed that teachers awarded high scores so that after moderation their students would remain with low scores. They knew the mode ration policy does not allow them to reduce scores beyond a certain point. Therefore, teachers deliberately gave students high scores because they knew that the marks will remain high even after moderation and generally the whole school will get high scores.

"I do have in mind that during moderation if I give 90 they will not reduce more than 20 so my student will get 70 and even the one poor in theory will be boosted" (FGD).

Participant 2 added:

"I cannot bring that school that has poor quality work down below you. Moderation policy does not allow that" (Participant 2).

Participant 3 shared the same sentiments that:

"They allocate high scores so that when they moderate the scores will be reduced to a certain extent".

This shows that there was a need for teachers and moderators to work together on assessment so that teachers understand what moderation is all about. Teachers inflate marks to ensure that even after moderation students remain with high scores as they think that moderation was about reducing marks.

\section{B. Discussion}

Factors that influenced the awarding of high scores in FN practical examination assessment included teacher competency levels, teachers' attitude towards assessment, unclear assessment tools, use of students' grades to judge teachers' performance etc. The findings of the study are in line with Ng'ang'a (2014) that an unsatisfactory marking scheme can be the principal source of unreliable marking. Examiners' marking to common standard and common interpretation of marking scheme is therefore important to ensure no student is disadvantaged or favoured. Kellaghan \& Greaney (2013) observation that some markers are characteristically generous, some strict and others may be inconsistent. Moskal (2013) argued that students' grades have become a judgment for their teachers' abilities and commitment. However, Inspectorate (2008) opined that in schools where practice was excellent, the standard of students' skills was generally very high. Adequate and well-maintained facilities are essential prerequisite for meeting the extensive requirements of practical coursework components in Consumer Science for all junior cycle and senior cycle programmes (Inspectorate, 2008). 
Cheung (2015) stated that majority of teachers experience difficult on how to assess practical work due to lack of proper teacher preparation and professional development programmes at both in-service and pre-service teacher training levels. Aslett (2016) attested to the fact that emotional factor can play a part in the marks that examiners award. An assessor can hope to remain objective throughout the assessment process, but where a marker is aware of a student's identity marking can be greatly affected (Aslett, 2016). In agreement with Stroud and Herold (2011), training could improve the consistency of each individual examiner's marking. Cizek (2016) argued that the lack of knowledge and interest in grading translates into a serious information breakdown in education and that reforming classroom assessment and grading practices will require educators' commitment to professional development and classroom-relevant training programs.

\section{CONCLUSIONS}

Based on the findings of the study, the researchers concluded that the lack of a clear and well defined marking tool. The tool needed to have a breakdown of marks as per the demand of each task and acceptable responses to each task. Teachers lacked training where they could be workshopped so that they acquire knowledge, assessment skills and practical skills to boost their confidence. Standardisation meetings can help teachers to understand the marking scheme and make the principal examiner's interpretation of the marking scheme clearly. ECESWA relied on teachers for practical assessment yet there was lack of monitoring by school head teachers, heads of departments and ECESWA hence, encouraging cheating and a laissez-faire attitude by the teachers. Teachers' desire to pass their students and knowledge of students' weaknesses contributed to teachers awarding high marks to undeserving students. Teachers also awarded high marks to protect their images, as students' poor performance would reflect badly on the teachers.

\section{RECOMMENDATIONS}

The study recommends the appointments of neutral examiners to avoid subject teachers being the external examiners, yet they are interested parties. Teachers should receive training on how to mark practical examinations. However, they should not mark for the classes that they teach.

\section{ACKNOWLEDGEMENTS}

The researchers would like to thank all the Food and Nutrition teachers in Eswatini, Regional Officers and the Consumer Science subject officer from the Examinations Council of Eswatini for sparing time in their busy schedules to participant in this study. I would also like to extend my sincere gratitude to my son Tadiwanashe for typing and typesetting this research article.

\section{REFERENCES}

Andrew, D. H \& Carol, C. Y. (2015). Descriptive Statistics for Modern Test Score Distributions- Skewness, Kurtosis, Discreteness, and Ceiling Effects. Educational and Psychological Measurement, 75(3), 365-388.

Aslett, J. (2016). Reducing variability, increasing reliability: exploring the psychology of intra-and inter-rater reliability. Investigations in university teaching and learning, 4(1), 223-232.

Brown, T. (2017). Describing a distribution of test scores. Retrieved from Ntweb.deltastate.edu/v.

Cambridge Report. (2017). Examination Council of Swaziland. Swaziland General Certificate of Secondary Education.

Cheung, D. \& Yip, D.Y (2015). Teachers concerns on Schoolbased assessment of practical work. Journal of Biological Education 39(4), 156-161.

Cizek, G. J. (2016). Grades: The Final Frontier in Assessment Reform. NASSP Bulletin. Reports Evaluative Journal, 80(584), 103.

Creswell, J. W. (2014). Research design: A qualitative, quantitative, and mixed methods approaches (4th Ed). United States of America: SAGE Publications.

Heald, J. (2018). Using Standard Deviation and Bell Curves for Assessment. Velag Wien: Springer Vienna.

Heynes, J. (2014). Qualitative Analysis of Fundamental Motor Skills. Australian Journal for Teacher Education, 41(3), 21-38.

Holroyd, M. (2015). The Influence of Contrast Effects Upon Teachers' Marks. Educational Research Journal, 39 (2), 229-233.

Inspectorate. (2008). Department of Education and Science. Brunswick Dublin: St. Flannan's College, CoClare.

Kellaghan, T. \& Greaney, V. (2013). Monitoring Performance: Assessment and Examinations in Africa. Association for the Development of Education in Africa. Mauritius: Grand Baie publishers.

Leepile, G. (2009). Assessing Home Economics coursework in senior secondary schools in Botswana. Assessment and Quality Assurance Education. University Of Pretoria. Faculty of Education.

Manana, R. H. (2016). Consumer Science Teachers' Experiences in the Implementation of School Based Assessment in Food and Nutrition Practicals in Eswatini. Unpublished paper, Examinations Council of Eswatini.

McSweeney, K. (2014). Assessment practices and their impact on Home Economics Education in Ireland. Ireland: The University of Stirling.

Moskal, B. M. (2013). Scoring Rubrics: What, When and How? Journal of Practical Assessment, Research \& Evaluation, 7(3), 1-7.

Nair, G., Setia, K., Samad, A., Zahri, R., Luqman, A., Vade, T. \& Che Nyah, H. (2014). Teachers' Knowledge and Implementation of School-Based Assessment: A Case Schools in Terengganu. Asian Social Science, 10(3), 23-30. 
Ng'ang'a, M.P. (2014). Effect of Marking Scheme on the Consistency of Scoring Mathematics Examinations. University of Nairobi School of Education. Department of Psychology.

OECD. (2013). The Organization for Economic Co-operation and Development. Education at a glance. Paris: Statistical Glossary.

Organization for Economic Co-operation and Development (2013). OECD. Education at a glance. Paris: Statistical Glossary.

Stroud, L. \& Herold, J. (2011). Who You Know or What You Know? Effect of Examiner Familiarity with Residents on OSCE Scores. Journal of the Association of American Medical Colleges, 86(10), 8-11. 